\title{
Estudio en la Comunidad Universitaria de la UAEH: Conocimiento y apego a las medidas preventivas contra COVID-19
}

\section{Study in the University Community of the UAEH: Knowledge and adherence of preventive measures against COVID-19}

\author{
Selene Téllez-Bardales ${ }^{a}$, Diana Ruíz-Amador ${ }^{b}$, Fernando Castelán-Islas $^{c}$, Frida Callejas- \\ Montes $^{d}$, Gustavo X. Cervantes-Castelán ${ }^{e}$, Diana M. Román-Zamora ${ }^{f}$, Diego Santos-Durán ${ }^{g}$, \\ Juan Hernández-Barrera ${ }^{h}$, Iván Hernández-Pacheco ${ }^{i .}$
}

\begin{abstract}
:
Coronavirus disease 2019 (COVID-19) is an infectious respiratory disease caused by a virus belonging to the Coronavirus family. To limit the transmission of this virus, precautions must be taken, so that throughout this pandemic a great discussion has been generated about the contamination and decontamination of inanimate surfaces. Most countries have used similar control strategies: measures that act on the environment, trying to decrease the virus load on the surfaces of furniture, clothing and other objects to avoid contact of susceptible hosts with the virus; personal hygiene measures such as frequent hand washing; and measures that act by cutting transmission from symptomatic or asymptomatic infected individuals to susceptible individuals.
\end{abstract}

Keywords:

virus; coronavirus; COVID-19; desinfection; surfaces; prevention; SARS-CoV-2

Resumen:

La enfermedad por coronavirus 2019 (COVID-19) es una enfermedad respiratoria infecciosa causada por un virus perteneciente a la familia de los Coronavirus. Para limitar la transmisión de este virus, se deben tomar precauciones, por lo que a lo largo de esta pandemia se ha generado una gran discusión sobre la contaminación y descontaminación de superficies inanimadas. La mayoría de los países han usado estrategias de control similares: medidas que actúan sobre el ambiente, intentando disminuir la carga del virus de superficies como muebles, vestimentas y otros objetos para evitar el contacto de huéspedes susceptibles con el virus; medidas de higiene personal tales como el lavado frecuente de manos; y medidas que actúan cortando la transmisión desde los individuos infectados sintomáticos o asintomáticos a los individuos susceptibles.

Palabras Clave:

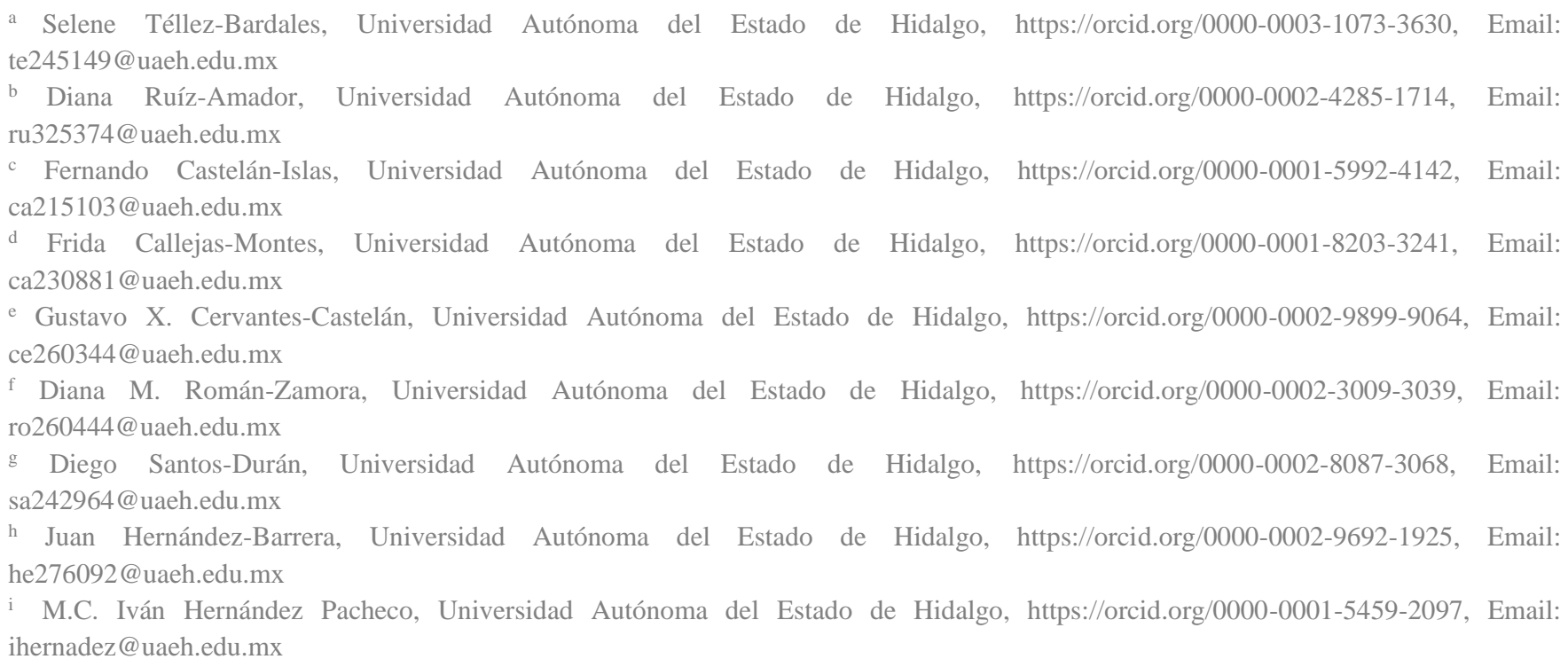

Fernando Castelán-Islas, Universidad Autónoma del Estado de Hidalgo, https://orcid.org/0000-0001-5992-4142, Email: ca215103@uaeh.edu.mx

Frida Callejas-Montes, Universidad Autónoma del Estado de Hidalgo, https://orcid.org/0000-0001-8203-3241, Email: ca230881@uaeh.edu.mx

Gustavo X. Cervantes-Castelán, Universidad Autónoma del Estado de Hidalgo, https://orcid.org/0000-0002-9899-9064, Email: ce260344@uaeh.edu.mx

Diana M. Román-Zamora, Universidad Autónoma del Estado de Hidalgo, https://orcid.org/0000-0002-3009-3039, Email: ro260444@uaeh.edu.mx

Diego Santos-Durán, Universidad Autónoma del Estado de Hidalgo, https://orcid.org/0000-0002-8087-3068, Email: sa242964@uaeh.edu.mx

h Juan Hernández-Barrera, Universidad Autónoma del Estado de Hidalgo, https://orcid.org/0000-0002-9692-1925, Email: he276092@uaeh.edu.mx

M.C. Iván Hernández Pacheco, Universidad Autónoma del Estado de Hidalgo, https://orcid.org/0000-0001-5459-2097, Email: ihernadez@uaeh.edu.mx

Fecha de recepción: 14/09/2020, Fecha de aceptación: 16/01/2021, Fecha de publicación: 05/06/2021 


\section{Introducción}

El 31 de diciembre de 2019, se informó a la oficina de la Organización Mundial de la Salud (OMS) en China de varios casos de neumonía de etiología desconocida, detectados en la ciudad de Wuhan, provincia de Hubei. ${ }^{1}$ El 9 de enero de 2020, el Centro Chino para el Control y la Prevención de Enfermedades identificó un nuevo coronavirus COVID-19 como el agente causante de este brote. El 30 de enero de 2020, con más de 9.700 casos confirmados en China y 106 casos confirmados en otros 19 países, el Director General de la OMS declaró que el brote era una emergencia de salud pública de interés internacional (PHEIC). El 11 de febrero, siguiendo las mejores prácticas de la OMS para nombrar nuevas enfermedades infecciosas humanas, se denominado a esta, "COVID-19", abreviatura de "Enfermedad por Coronavirus 2019". 2

Para el 11 de marzo de 2020 la OMS determina en su evaluación que la COVID-19 se caracterizaba como una pandemia, debido a sus características de propagación, gravedad, y por los niveles también alarmantes de inacción. ${ }^{3}$

La enfermedad respiratoria infecciosa causada por el SARS-CoV-2 es provocada por un nuevo virus que pertenece a la subfamilia Orthocoronavirinae, género Coronavirus y al subgénero Sarbecovirus (betacoronavirus, beta-2b) y dentro de ellos al clado o linaje $2 .{ }^{4}$

Se denominan coronavirus por la apariencia que dan bajo el microscopio electrónico parecido a una corona. Son virus envueltos, con un diámetro aproximado de $125 \mathrm{~nm}$, genoma ARN de cadena simple, sentido positivo. Se considera el genoma más grande de los virus ARN con un tamaño de 26-32 kilobases, codifica cuatro proteínas estructurales que incluyen glicoproteína espiga $(\mathrm{S})$, envoltura $(\mathrm{E})$, membrana $(\mathrm{M})$ y nucleocápside $(\mathrm{N})$ y otras 16 proteínas no estructurales que participan en la transcripción y replicación viral como es la helicasa y la ARN polimerasa dependiente de ARN.

Los coronavirus humanos a través de su proteína espiga se unen a uno de los receptores, éstos pueden ser: la enzima convertidora de angiotensina, dipeptidil peptidasa 4, aminopeptidasa $\mathrm{N}$ y O-acidoacetil siálico, e ingresan a la célula a través de una vía endosómica y/o no endosómica; una vez ingresado, se libera la nucleocápside y el ARN en el citoplasma, se sintetizan las enzimas que participan en la transcripción y replicación del virus, se producen copias ARN de sentido negativo, por medio de ARN subgenómicos se producen las proteínas estructurales que posteriormente serán ensambladas y se libera el virión a través de exocitosis al espacio extracelular. ${ }^{5}$

Una persona infectada puede experimentar síntomas después de un período de incubación que puede variar de alrededor de 2 a 14 días (rara vez ha habido casos de incubación de 29 días), tiempo durante el cual la persona aún podría ser contagiosa. Para limitar la transmisión, se deben tomar precauciones, como adoptar una higiene personal cuidadosa, lavado de manos frecuente y el uso de mascarilla.

El Coronavirus afecta el tracto respiratorio inferior y causa una serie de síntomas descritos como similares a la gripe, entre ellos se puede presentar, fiebre, tos, dificultad para respirar, dolor muscular, cansancio y molestias gastrointestinales como diarrea. En casos severos, puede ocurrir neumonía, síndrome de dificultad respiratoria aguda, sepsis y shock séptico, hasta la muerte del paciente.

En las últimas semanas ha habido una gran discusión sobre la contaminación y descontaminación de superficies inanimadas. De hecho, la duración antes de la inactivación del virus COVID-19 en superficies (líquidas, sólidas o gaseosas) todavía se debate. En la mayoría de los casos, se produce la propagación entre las personas a través de las gotas respiratorias emitidas por un individuo infectado al toser o estornudar, que luego son inhaladas por una persona sana que está cerca. Existe información basada en estudios realizados durante epidemias previas causadas por coronavirus (SARS coronavirus y MERS coronavirus) la cual demuestra que pueden persistir en superficies inanimadas como metal, vidrio, plástico por alrededor de 9 días y que con adecuada desinfección se disminuye de forma considerable el tiempo y por lo tanto su transmisión. ${ }^{6}$

Se han hecho estudios sobre la vida media de COVID-19 en algunas superficies como se enumeran a continuación: Aerosoles: 3 horas, plástico: 72 horas, acero inoxidable: 48 horas, cobre: 4 horas, cartulina: 24 horas. $^{7}$

Evidencia reciente indica que la supervivencia del virus COVID-19 (SARSCoV-2) en las superficies es similar a la del SARS-CoV1, el virus que causa el síndrome respiratorio agudo severo (SARS), con una supervivencia en superficies que van desde 2 horas hasta los 9 días.

El tiempo de supervivencia depende de varios factores, incluyendo el tipo de superficie, temperatura, humedad relativa y la cepa del virus. El mismo estudio también encontró que la inactivación efectiva se puede lograr en 1 minuto usando desinfectantes comunes, como $70 \%$ de etanol o $0.1 \%$ hipoclorito de sodio. 
La provisión de agua segura, saneamiento e higiene son condiciones esenciales para proteger la salud humana durante todos los brotes de enfermedades infecciosas, incluida la enfermedad por coronavirus (COVID-19). ${ }^{8}$

Las siguientes son medidas básicas que se han sugerido tanto por organismos nacionales e internacionales, luego de diversos estudios para la disminución de la transmisión de la enfermedad por COVI19.

\section{Limpieza de superficies}

En cualquier área la limpieza debe efectuarse con el siguiente orden: iniciarla desde las zonas menos sucias progresando hacia las más sucias y de las más altas a las más bajas. En general, la limpieza debe ser realizada con movimientos en una sola dirección, para no volver a ensuciar las áreas que ya han sido limpiadas. Las superficies más altas deben limpiarse con un paño/tela/franela/toalla/jerga impregnada con agua con detergente, evitando dispersar el polvo. Las paredes, ventanas y puertas que incluyen las manijas deben limpiarse en forma regular, además de cuando estén visiblemente sucias. Las superficies horizontales que incluyen mesas, sillas, camas, repisas $u$ otras instalaciones adheridas a la pared deben limpiarse con un paño con agua con detergente, enjuagarse con agua limpia y desinfectarse con solución clorada (ver más adelante técnica de los tres baldes). Si el material de la superficie que se desea limpiar es sensible al detergente o solución clorada se recomienda realizar la limpieza con solución de alcohol al $70 \%$.

\section{Técnica de limpieza de los tres baldes}

La técnica por emplear será la de arrastre por medios húmedos, el tallado/fregado/trapeado es la acción más importante, ya que provoca la remoción física de los microorganismos.

Consiste en los siguientes tres tiempos: lavado y tallado con agua jabonosa y/o detergente, enjuagado y secado y desinfección con solución clorada.

Elementos para utilizar: 3 baldes (cubetas), 3 trapos/jerga/microfibra, solución detergente (preparada en el momento), solución desinfectante (solución clorada) preparada al momento y escobilla para inodoros.

Para la realización de esta actividad es necesario que las personas cuenten con el equipo adecuado de protección personal lo que evita una contaminación, se deben utilizar guantes desechables para la limpieza de superficies, ropa o suelo, el equipo de protección debe tener una adecuada disposición después de su uso, por lo que se requiere capacitación para las personas de limpieza. ${ }^{9}$

\section{Higiene de manos}

A mediados del siglo XIX, gracias a los estudios de Ignaz Semmelweis y Oliver Wendell Holmes, se estableció que las infecciones adquiridas en hospitales eran transmitidas a través de las manos de los trabajadores de la salud. Semmelweis, quien laboraba en una clínica obstétrica de la Universidad de Viena, se percató de una tasa de mortalidad materna elevada (17\%) asociada mayormente a fiebre puerperal. También, observó que médicos y estudiantes que laboraban en la clínica, ingresaban directamente a la atención de partos tras realizar autopsias, y que portaban un olor desagradable en las manos, aún después de realizar un lavado con agua y jabón previo a entrar a la clínica. Semmelweis teorizó que, tras realizar alguna autopsia, "partículas cadavéricas" permanecían en las manos de los médicos, mismas que causaban, posteriormente, fiebre puerperal en las pacientes obstétricas que atendían. Ignaz propuso la desinfección de manos con hipoclorito cálcico, previo a la atención de pacientes obstétricas, reduciendo así, la tasa de mortalidad materna, de un $17 \%$, a $3 \% .^{10}$

Varias literaturas describen el frotamiento de manos con sustancias a base de alcohol (ABHR por sus siglas en inglés), como más efectivo que el lavado de manos con jabón antimicrobiano. También, los ABHR tienen mejor eficacia en la remoción de diferentes virus, en comparación con el lavado con agua y jabón antimicrobiano, sugiriendo que los ABHR proporcionan mayor protección contra virus respiratorios y entéricos. ${ }^{11}$

La higiene de manos, ya sea con agua y jabón, o con productos a base de alcohol, son partes esenciales de higiene y producen beneficios significativos en cuanto a la reducción de incidencia de infecciones ya sea de tracto respiratorio o gastrointestinal, especialmente contra patógenos conocidos como causantes de infecciones por falta de higiene de manos (norovirus, rotavirus, rinovirus, influenza, entre otros).

Los jabones son productos detergentes que contienen ácidos grasos esterificados e hidróxido de sodio o potasio. Su actividad higiénica puede ser atribuida a que provocan la remoción de partículas lipídicas adherentes, así como otras sustancias orgánicas encontradas en las manos. Los jabones comunes tienen una mínima actividad antimicrobiana, aunque el lavado de manos con jabón común puede remover flora laxamente adherida.

La mayoría de los preparados antisépticos con base de alcohol contienen etanol, isopropanol o npropanol, o una combinación de estos dos últimos. Su actividad antimicrobiana se debe a su capacidad de 
desnaturalizar proteínas, siendo los preparados con concentración de $60-80 \%$ de alcohol las más efectivas. Los alcoholes tienen una actividad in-vitro excelente contra bacterias gram-positivas y gram-negativas, $M$. Tuberculosis y una variedad de hongos, sin embargo, no tienen actividad contra esporas bacterianas $u$ ooquistes protozoarios. Los virus envueltos como influenza y herpes simple, son susceptibles en pruebas in-vitro.

En el año 2009, la OMS publicó los lineamientos para la higiene de manos con enfoque en la atención de la salud, incluyendo dentro de estas, los llamados 5 momentos para la higiene de manos, dichos momentos son: 1. Antes de tocar al paciente, 2. Antes de realizar alguna tarea aséptica, 3. Después del riesgo de exposición a líquidos/fluidos corporales, 4. Después de tocar al paciente, 5. Después del contacto con el entorno del paciente. ${ }^{12}$

El lavado de manos como indica el Instituto Mexicano del Seguro Social debe tener una duración promedio de 40 a 60 segundos y consta de 10 pasos, para la desinfección de manos con gel alcohol está indicada una duración promedio de 20 a 30 segundos para que esta sea efectiva y consta de 8 pasos (se pueden consultar las infografías en las referencias). ${ }^{13}$

\section{Distanciamiento social, ¿Por qué es importante?}

Limitar el contacto frente a frente con otras personas es la mejor forma de reducir la propagación de la enfermedad del coronavirus 2019 (COVID-19). El distanciamiento social, también llamado "distanciamiento físico", significa mantener un espacio o distancia física de al menos 6 pies entre una persona y otra o el equivalente a un metro y medio como mínimo para así evitar y disminuir los contagios. Para ejemplificar un modo práctico de medir la distancia que se debe mantener, podemos utilizar la medida del largo de 2 brazos extendidos con respecto a otras personas. ${ }^{14}$

Una de las principales rutas descrita de transmisión del SARS-CoV2 es a través de la propagación de gotas de saliva (gotitas de Flügge) que van de una persona a otra, para lo que se necesita un contacto cercano. En un intento por mitigar la pandemia de COVID19, muchos países han adoptado políticas de distanciamiento físico sin precedentes, además de exhortar a las personas a quedarse en casa y evitar salir, con las excepciones de aquellos que realizan trabajos esenciales y para la compra de artículos indispensables. ${ }^{15}$

Transmisión de COVID-19 al tocarse los ojos, nariz o boca.
Tocarse la cara, especialmente las mucosas de ojos, nariz o boca, es un acto instintivo del ser humano, sin embargo ante la emergencia sanitaria por COVID-19 resulta una conducta de riesgo, ya que a través del contacto con estos, se puede aumentar la probabilidad ya sea de transmitir o adquirir el virus, recordando que nuestras manos están la mayor parte del tiempo en contacto con todo tipo de superficies, las cuales constituyen el vehículo idóneo para la transmisión, esto sumado a que es en ocasiones es difícil la desinfección total de las superficies y a que dicho acto tiene una duración de efectividad muy variable. ${ }^{16}$

Las gotas producidas en el estornudo o durante el habla (gotitas de Flügge) que contienen el virus, pueden caer sobre los objetos y superficies que rodean a la persona, como mesas, ropa y objetos personales, de modo que otras personas pueden infectarse si tocan esos objetos o superficies y luego de esto en un acto involuntario llega a tocarse los ojos, nariz o boca, por ello la importancia que se le ha atribuido al lavado de manos constante, así como el evitar tocarse la cara. ${ }^{17}$

\section{Uso de Mascarilla quirúrgica, mascarilla N95 e higiene respiratoria}

Desde el brote de SARS-Cov-2 en China el uso de mascarillas quirúrgicas, respiradores N95 y demás equipo de protección respiratoria se ha vuelto imprescindible para la sociedad, no solo en los países de Medio Oriente sino también en el continente Americano, existen ciertas discrepancias respecto a los resultados obtenidos por distintos estudios alrededor del mundo sobre el uso de mascarillas en áreas no clínicas, no obstante por ahora las recomendaciones son el uso de mascarillas quirúrgicas de triple capa termo selladas en áreas comunes, además de la distancia de 1 y 1.5 metros que se debe mantener entre persona y persona. La evidencia sugiere que la COVID-19 podría transmitirse antes del inicio de los síntomas, la transmisión comunitaria podría reducirse si todos, incluidas las personas que han sido infectadas, pero están asintomáticos normalice el uso de mascarilla. ${ }^{18}$

Según la información disponible, las rutas de transmisión más comunes del síndrome respiratorio agudo severo (SARS-CoV-2) o COVID-19 es por la transmisión de gotas a través del contacto directo cara a cara entre pacientes y proveedores de atención dental (DHCP) o entre el personal médico al realizar procedimientos de generación de aerosoles como laringoscopia, la intubación y extubación de pacientes. El virus SARS-CoV-2 tiene afinidad por el receptor de la enzima convertidora de angiotensina 2 (ACE-2), que abunda en el tracto respiratorio y el epitelio del conducto de las glándulas salivales, por lo tanto, la saliva contiene una alta carga viral. El tamaño de las partículas que se 
han reportado van de $0.5-10 \mu \mathrm{m}$, este dato es de importancia ya que se ha demostrado que la transmisibilidad a través de las actividades que generan aerosoles son un factor de riesgo en el personal de salud, y es en estos casos cuando el uso de las mascarillas tipo respirador N95 se vuelve fundamental ya que es el único capaz de filtrar partículas tan pequeñas como los aerosoles producidos en ambientes hospitalarios durante ciertos procedimientos invasivos de la vía aérea. ${ }^{19}$

Como ya se mencionó anteriormente, una de las medidas de prevención adoptadas por muchos países para evitar la propagación de la COVID-19 ha sido el uso de las mascarillas quirúrgicas, se recomienda su uso basado en 2 estudios observacionales que determinaron que el uso comunitario de mascarillas posiblemente se asoció con un menor riesgo de infección por SARS-CoV1. En entornos de atención de salud de riesgo alto o moderado, los estudios observacionales encontraron que el riesgo de infección por SARS-CoV-1 y el coronavirus del síndrome respiratorio del Medio Oriente disminuyó con el uso de mascarillas versus no uso, así mismo, disminuyó con N95 versus el uso de mascarillas quirúrgicas. Los ensayos aleatorios en entornos comunitarios no encontraron diferencias entre N95 versus máscaras quirúrgicas y ninguna diferencia entre el riesgo. ${ }^{20}$

Evidencia sugiere que las mascarillas médicas y los respiradores N95 ofrecen una protección similar contra la infección viral respiratoria, incluido el coronavirus en los trabajadores de la salud durante la atención que no genera aerosoles, de la misma manera, presenta protección en el entorno comunitario, por lo que el uso de mascarilla quirúrgica se recomienda para evitar la propagación del SARS-COV 2. Es de importancia considerar la preservación de respiradores N95 para procedimientos de alto riesgo que generan aerosoles, únicamente para el uso médico. ${ }^{21}$

Algunos artículos mencionan que el uso de mascarillas comunitarias para personas sanas podría ser beneficioso, particularmente para COVID-19, donde la transmisión puede ser pre-sintomática. En la comunidad, las máscaras parecen ser efectivas con y sin higiene de manos, y ambas en conjunto son más protectoras. Por otra parte, los estudios de uso de mascarillas como control de las posibles fuentes de contagio sugieren un beneficio, y adquieren relevancia durante la pandemia de COVID-19 como medida universal para la prevención y mitigación de la enfermedad. ${ }^{22}$

\section{Estornudo de etiqueta}

El Centro Médico de Maine, el Centro Médico Regional de Saint Mary en asociación con la Asociación Médica de Maine publicó un video del Dr. Ben Lounsbury que muestra cómo toser en el codo. Esta parece ser una de las primeras explicaciones documentadas sobre cómo realizar la maniobra y el porqué de su uso.

La OMS y otras agencias médicas continúan recomendando la aplicación y el cumplimiento de las medidas preventivas básicas para el control de infecciones conocidas como intervenciones no farmacéuticas (INP), las cuales son la piedra angular para prevenir la transmisión de enfermedades propensas a generar epidemias por propagación de gotas en los centros de salud. El término "estornudo de etiqueta" ha evolucionado desde que lo describieron Bone A, et al. ${ }^{23}$ Las infecciones respiratorias generalmente se transmiten a través de partículas en el aire, que puede liberarse al hablar o toser. Para evitar infecciones respiratorias causadas por transmisión aérea, el Centro Para el Control y Prevención de Enfermedades agregó recomendaciones como la higiene respiratoria / estornudo de etiqueta a su lista de medidas preventivas y anuncian la importancia de su uso. Por lo tanto, es esencial, que el público en general conozca y practique estas medidas para evitar las infecciones de vías respiratorias. ${ }^{24}$

\section{Metodología}

Planteamiento del problema: ¿Cuáles son las medidas preventivas que conoce y aplica de forma correcta la Comunidad Universitaria de la UAEH?

Se realizó una búsqueda exhaustiva de información referente a la enfermedad por COVID-19 en distintas plataformas y bases de datos dedicadas a la investigación y publicación de material en relación a las ciencias de la salud (PubMedCentral) así como sitios de organismos nacionales e internacionales reguladores de los servicios de salud (OMS, OPS, Secretaría de Salud de México, Instituto Mexicano del Seguro Social); posteriormente se analizaron los documentos obtenidos y se elaboraron los antecedentes en base a los resultados de distintos estudios y a recomendaciones oficiales dadas a la población por organismos de salud, los cuales nos permitieron tener un panorama más específico y así conocer las medidas de prevención con mayor evidencia de efectividad, las cuales se convirtieron en nuestras variables en el estudio transversal, observacional y descriptivo que se realizó; nuestro instrumento de evaluación fue la encuesta "Estudio en la Comunidad Universitaria de la UAEH: Conocimiento y apego a las medidas preventivas contra COVID-19" realizada a través 
de Google Forms, dirigida a alumnos, catedráticos y personal administrativo de la Universidad Autónoma del Estado de Hidalgo.

\section{Objetivo General}

Identificar cuáles son las medidas preventivas contra COVID-19 que conoce y aplica de forma correcta la Comunidad Universitaria.

\section{Objetivos específicos}

- Identificar los métodos de desinfección de manos más comunes para la disminución de la transmisión del COVID-19 en la población universitaria de la UAEH.

- Identificar si se utiliza de manera correcta la mascarilla y los espacios donde más frecuentemente se utiliza como medida para la disminución de la transmisión de COVID-19 en la población universitaria.

- Identificar si se realiza o no de manera rutinaria la limpieza y desinfección de superficies, así como el uso adecuado de productos de limpieza.

- Identificar si la Comunidad Universitaria conoce y aplica correctamente el estornudo de etiqueta.

- Identificar en la Comunidad Universitaria el conocimiento y apego de la sana distancia.

- Identificar las medidas que requieren reforzamiento para la implementación de estrategias que influyan en su correcta aplicación.

\section{Resultados}

Se elaboró y aplicó una encuesta a individuos que forman parte de la Universidad Autónoma del Estado de Hidalgo (alumnos, catedráticos y administrativos) a través de la plataforma de Google Forms como parte del "Estudio en la Comunidad Universitaria de la UAEH: Conocimiento y apego a las medidas preventivas contra COVID-19". La encuesta está conformada por 16 preguntas, todas de opción múltiple. Se contó con la participación de 2240 sujetos, obteniéndose los siguientes resultados:

$$
\text { Sexo }
$$$$
\text { 2,240\&nbsp:respuestas }
$$

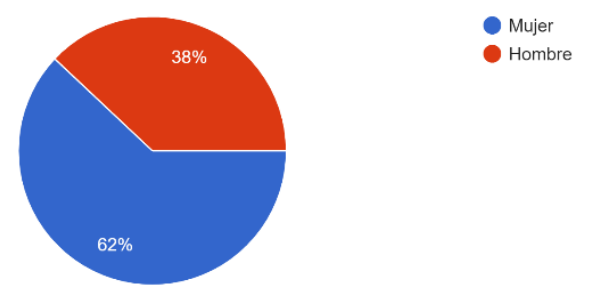

Figura 1. "Sexo", del total de encuestados, $62 \%$ (1389) fueron mujeres y $38 \%$ (851) hombres.
"Edad", el rango de edad de los participantes fue de los 15 años hasta más de 60 años, con una mayor prevalencia para el grupo de edad de 15 a 20 años con 787 participantes lo que representó el $35.1 \%$ de todos los participantes, el grupo de 21 a 25 años tuvo 474 (21.2\%) participantes, 26 a 30 años 137 (6.1\%), 31 a 35 años 177 (7.9\%), 36 a 40 (años 171 (7.6\%), 41 a 45 años 110 (4.9\%), 46 a 50 años 118 (5.3\%), 51 a 55 años 115 (5.1\%), 56 a 60 años $85(3.8 \%)$ y para el grupo de edad de más de 60 años se contó con la participación de 66 (2.9\%) personas (Figuras 2 y 3 ).

La importancia de conocer el rango de edad de los encuestados es útil para la elaboración de estrategias de prevención entorno a los grupos etarios, así como la identificación de posibles factores de riesgo.

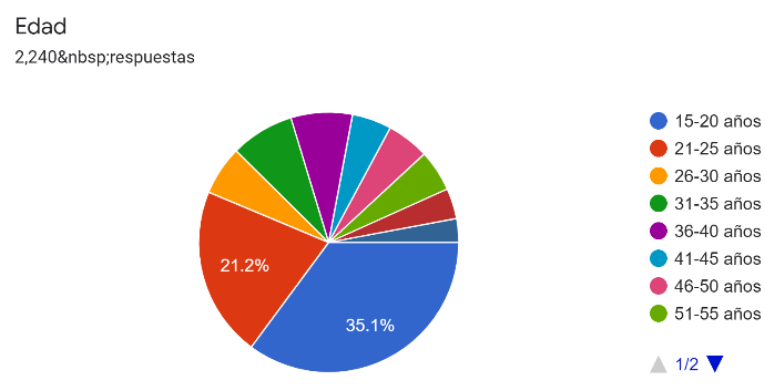

Figura 2. Edad de los encuestados.
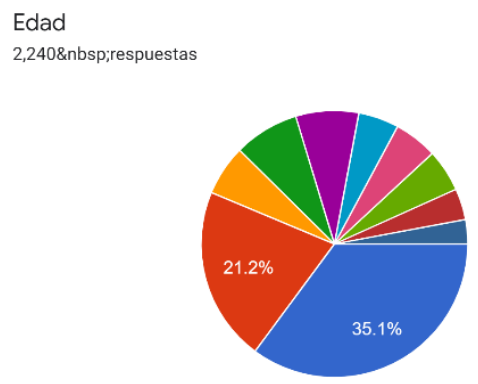

- 56-60 años Más de 60 años $\Delta 2 / 2 \nabla$

Figura 3. Edad de los encuestados.

¿A qué escuela/instituto perteneces?, esta pregunta contaba con 22 opciones correspondientes a cada una de las escuelas e institutos que conforman la UAEH, el Instituto de Ciencias Básicas e Ingeniería (ICBI) fue el instituto con mayor número de participantes con 541 lo que representó el $24.1 \%$ del total de encuestados, ES Atotonilco de Tula 429 (19.2\%), Instituto de Ciencias Sociales y Humanidades (ICSHu) 312 (13.9\%), ES Huejutla 234 (10.4\%), ES Actopan 170 (7.6\%), Instituto de 
Ciencias Agropecuarias (ICAp) 138 (6.2\%), Preparatoria número $2(6 \%)$, Institutos de Ciencias de la Salud (ICSa) 103 (4.6\%), Institutos de Artes (IDA) 65 (2.9\%), ES Zimapán 54 (2.4\%), Preparatoria número 518 (0.8\%), Instituto de Ciencias Económico Administrativas (ICEA) 16 (0.7\%), ES Tizayuca 9 (0.4\%), ES Cd. Sahagún 8 (0.3\%), Preparatoria número $13(0.1 \%)$, Preparatoria número 42 (0.08\%), ES Apan 2 (0.08\%), ES Tepeji de Rio 2 (0.08\%), Preparatoria número 71 (0.04\%) (Figuras 4, 5, y 6).

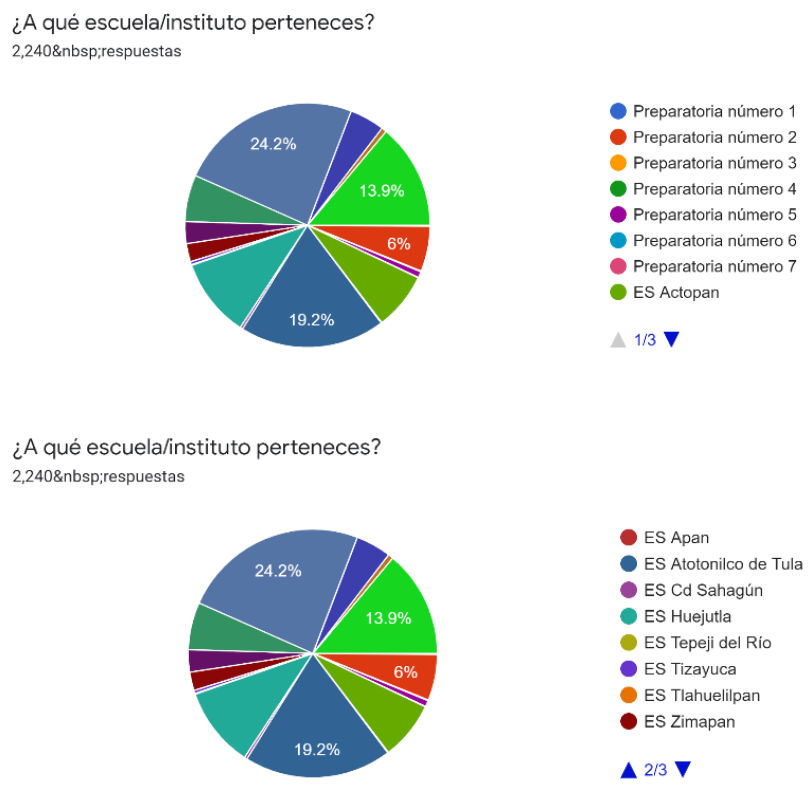

¿A qué escuela/instituto perteneces? 2,240\&nbsp;respuestas
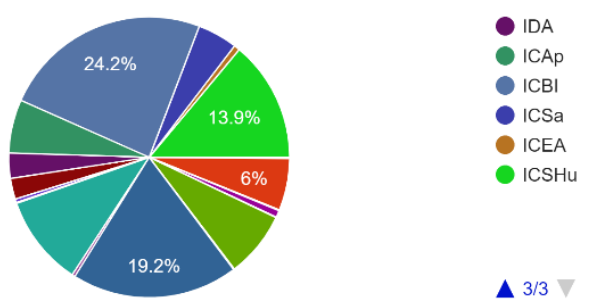

Figuras 4-6. Instituto a donde pertenecen los encuestados.

¿Qué tipo de desinfección de manos realiza de manera más frecuentemente?, se encontró que $76.9 \%$ (1712) de los encuestados refieren desinfectar sus manos de manera más frecuente con agua y jabón, 22.9\% (512) se desinfecta las manos con alcohol gel y solo el $0.7 \%$ (16) refieren hacerlo con alguna otra sustancia (Figura 7$)$.
¿Qué tipo de desinfección de manos realiza de manera más frecuentemente? 2,240\&nbsp;respuestas

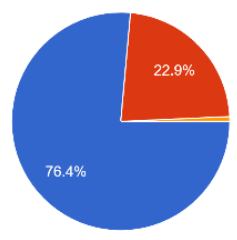

- Lavado de manos con agua y jabón - Desinfección con alcohol en gel Desinfección con otro tipo de productos
(clorhexidina, yodo...)

Figura 7. Métodos de desinfección.

¿Cuánto tiempo tarda en realizar el lavado de manos con agua y jabón?, el 50.1\% (1123) de los encuestados refiere realizar un lavado de manos con una duración promedio de 20 a 40 segundos, el 23.5\% (527) refiere tardar máximo 20 segundos, 19.7\% (442) tarda de 40 a 60 segundos y el $6.6 \%$ (148) dice tardar más de 60 segundos al lavar sus manos (Figura 8 ), estos resultados nos muestran que la gran mayoría de la población encuestada no sigue las recomendaciones emitidas por el Instituto Mexicano del Seguro Social, el cual menciona que la duración promedio de una correcta técnica de lavado de manos debe durar en promedio de 40 a 60 segundos, tan solo el $19.7 \%$ de los encuestados refieren hacerlo en este tiempo, es importante la elaboración de una estrategia didáctica que permita el conocimiento de la correcta técnica de lavado de manos y con ello el tiempo requerido para la realización de la misma.

¿Cuánto tiempo tarda en realizar el lavado de manos con agua y jabón? 2,240\&nbsp:respuestas

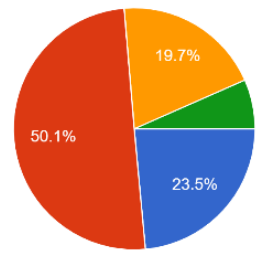
- De 40 a 60 segundos 60 segundos o más

Figura 8. Tiempo del lavado de manos.

¿Cuánto tiempo tarda en desinfectar sus manos con gel antibacterial (solución gel alcohol) ?, el $52.1 \%$ (1166) de los participantes refieren tardar 20 segundos como máximo en la desinfección de manos con gel alcohol, 38\% (851) de 20 a 40 segundos, $7.8 \%$ (175) tarda de 40 a 60 segundos y el $2.1 \%$ (48) lo hace en 60 segundos o más (Figura 9). Al igual que en el apartado de desinfección de manos con agua y jabón, la mayoría de los encuestados no realiza la técnica con gel alcohol en el tiempo establecido por el Instituto Mexicano del Seguro Social que se ha demostrado es el indispensable para la neutralización de virus y bacterias. 
¿Cuánto tiempo tarda en desinfectar sus manos con gel antibacterial (solución gel alcohol)? $2,240 \&$ nbsp;respuestas

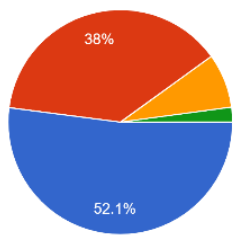

20 segundos como máximo

De 20 a 40 segundos

De 40 a 60 segundos

- 60 segundos o más

Figura 9. Tiempo de desinfección.

Durante el desarrollo de esta pandemia, ¿Qué cantidad de jabón consume en su hogar o lugar donde pasa más tiempo?, el $74.5 \%$ (1669) de los encuestados refieren gastar más jabón de manos desde el inicio de la Pandemia, el 15.3\% (342) refiere que no se percató de la cantidad de jabón que regularmente consume, el 10\% (224) dice consumir la misma cantidad que siempre ha utilizado, y la opción de "menos cantidad" no fue seleccionada por ninguno de los encuestados (Figura 10). Este ítem está relacionado de manera directa con la pregunta sobre el tipo de desinfección de manos que más frecuentemente realiza la población de la UAEH, la cual fue el lavado de manos con agua y jabón.

Durante el desarrollo de esta pandemia, ¿Qué cantidad de jabón consume en su hogar o lugar donde pasa más tiempo?

2,240\&nbsp;respuestas
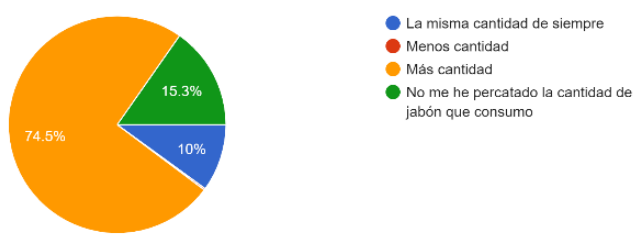

Figura 10. Cantidad de jabón.

¿Cuál de las siguientes superficies desinfecta a diario ya sea con, alcohol gel $70 \%$, cloro diluido $u$ otro desinfectante?, el $67.1 \%$ (1503) selecciono la respuesta de todas las anteriores (mesas, manijas y baños), el $20.9 \%$ (469) desinfecta más frecuentemente mesas, $6.7 \%$ (149) manijas y el 5.3\% (119) baños (Figura 11).

Los resultados reflejan que una gran proporción de los encuestados refieren desinfectar la mayoría de las superficies con las que frecuentemente tienen contacto, la importancia de ello radica en la permanecía del virus sobre las diversas superficies lo que las convierte en un reservorio para este y la posibilidad del contacto de las manos y las mucosas de ojos, nariz o boca con el mismo, por ello fomentar la limpieza constante de todas las superficies antes y después de su uso es una estrategia de vital importancia para cortar la cadena de propagación y contagio.
¿Cuál de las siguientes superficies desinfecta a diario ya sea con, alcohol al 70\%, cloro diluido u otro desinfectante? 2,240 \&nbsp;respuestas
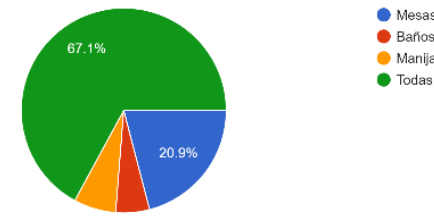

- Manijas

Figura 11. Superficies que desinfectan.

¿Cuál es la dilución de cloro y agua que se debe realizar para la limpieza de superficies?, el 46.7\% (1046) desconoce la cantidad correcta de cloro por cada litro de agua, $31.9 \%$ (715) selecciono la opción de $10 \mathrm{ml}$ por cada litro de agua, $14.2 \%$ (318) dijo que la dilución es $5 \mathrm{ml}$ de cloro por cada litro de agua y 7.2\% (161) $100 \mathrm{ml}$ de cloro por cada litro de agua.

Las respuestas obtenidas para este ítem dentro de la encuesta nos hacen ver las estrategias de desinfección de superficies que necesitan ser reforzadas o dadas a conocer de manera más amplia dentro de la población, su importancia radica en que la desinfección constante de superficies con las sustancias adecuadas es una medida eficaz en la erradicación del COVID-19 (Figura 12).

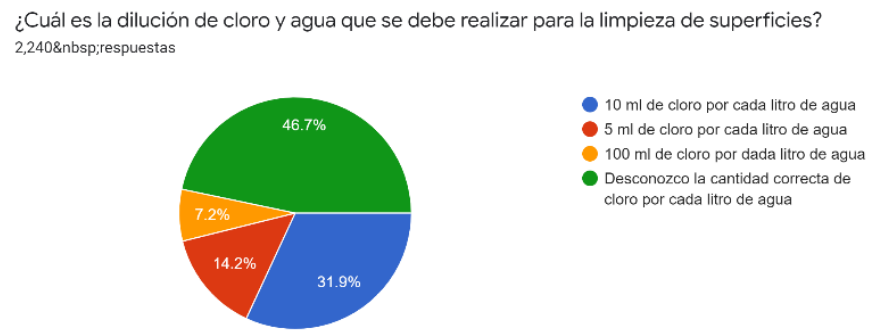

Figura 12. Dilución de cloro y agua.

¿En qué consiste el estornudo de etiqueta?, $94.2 \%$ (2109) de los encuestados eligió que el estornudo de etiqueta consiste en cubrir con el ángulo interno de codo, la nariz y boca al estornudar o toser, $4.5 \%$ (100) dijo que consiste en toser y estornudar sobre el antebrazo, $1 \%$ (23) estornudar sobre el brazo y $0.4 \%$ (8) seleccionó que consistía en estornudar sobre la mano (Figura 13). Esta es una medida importante de prevención cuya difusión pareciera ser la adecuada ya que casi la totalidad de los encuestados seleccionó la definición correcta del estornudo de etiqueta, de igual forma es importante seguir reforzando la media para que sea un concepto conocido y aplicado por la totalidad de la Comunidad Universitaria y la población en general. 
¿En qué consiste el estornudo de etiqueta? 2,240\&nbsp;respuestas

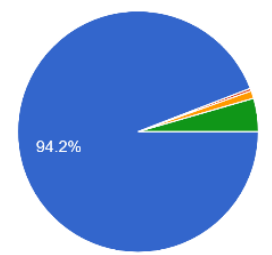

Figura 13. Estornudo de etiqueta.

¿Qué tan frecuente se realiza la limpieza con jabón y solución clorada, dentro de su hogar?. 46.4\% (1040) dice realizarla 1 vez al día, 39.6\% (886) 2 a 3 veces por semana, 11\% (246) 1 vez por semana y el 3\% (68) dice no realizar la limpieza de su hogar, esta última se puede referir a que la persona que contestó la encuesta no es la persona responsable de la realización de la limpieza de su hogar por lo que seleccionó esta última respuesta (Figura 14).

¿Qué tan frecuente se realiza la limpieza con jabón y solución clorada, dentro de su hogar? 2,240\&nbsp;respuestas

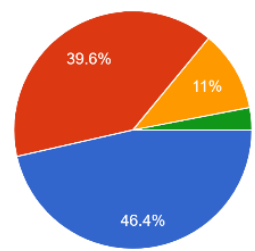

1 vezal dia

2 a 3 veces por seman

1 vez a la seman

- No la realizo cubrir con el ángulo in

er sobre la mano

Consiste en estornudar sobre el bra Consiste en toser y estornudar sobr antebrazo

Figura 14. Frecuencia de la limpieza

¿Conoce cuál debe ser la sana distancia correcta mínima entre una persona y otra para reducir la transmisión del COVID-19?, 42.6\% (955) selecciono que la distancia mínima es de 1 metro, el 33.4\% (748) dijo que es la longitud aproximada de dos brazos, 23\% (515) dijo que la distancia mínima es de medio metro y el 1\% (22) dijo desconocer la distancia mínima requerida para disminuir la transmisión del virus (Figura 15).

En diversos estudios se ha visto reflejado el beneficio del distanciamiento social, por lo que es una medida implementada como estrategia para cortar la cadena de propagación de COVID-19 dentro de la población, el conocimiento de la correcta distancia que debe mantener una persona de otra, permitirá que esta medida adquiera un mayor impacto, y con los resultados obtenidos se convierte al igual que otras en una medida cuya difusión debemos reforzar dentro de nuestra Comunidad Universitaria.

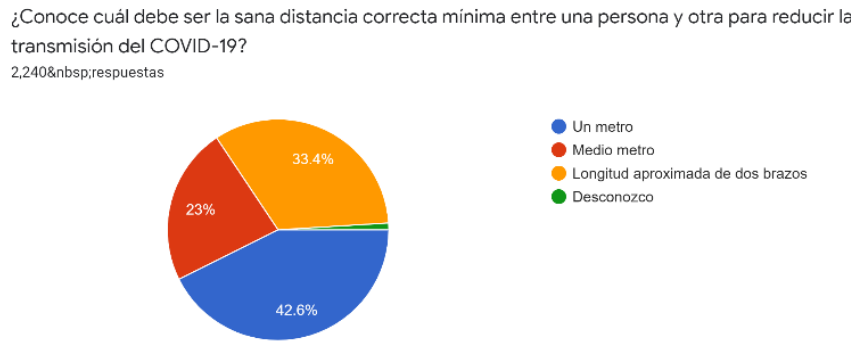

Figura 15. Sana distancia.

¿Qué tan frecuentemente usted se toca ojos, nariz o boca en el trascurso del día?, el 45.9\% (1028) dijo que a veces suele tocarse ojos, nariz o boca, $24.9 \%$ (558) casi nunca, $18.7 \%$ (419) se toca la cara frecuentemente y $10.5 \%$ (235) lo hace muy frecuentemente (Figura 16).

¿Qué tan frecuentemente usted se toca ojos, nariz o boca en el transcurso del dia? $2,240 \&$ nbsp;respuestas

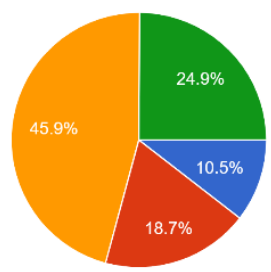

Muy frecuentemente

- Frecuentemente

A veces

Casi nunca

Figura 16. Frecuencia de contacto con ojos, nariz o boca.

De forma habitual, ¿Cómo utiliza el cubrebocas?, 98.5\% (2207) utiliza el cubrebocas cubriendo nariz y boca, $0.8 \%$ (17) dice que casi nunca utiliza cubrebocas, el $0.5 \%$ (11) lo usa cubriendo únicamente la boca, la opción "No utilizo cubrebocas", no fue seleccionada por ninguno de los participantes (Figura 17).

Al parecer la difusión de la información a lo largo de estos meses referente al correcto uso del cubrebocas han sido efectivas, ya que el $98.5 \%$ de los encuestados seleccionaron la respuesta que indica el uso correcto del cubrebocas, aun así, y debido a la efectividad de esta medida de protección y contención es importante seguir difundiendo su uso, para así lograr que el 100\% de la comunidad haga el correcto uso de este.

De forma habitual, ¿Cómo utiliza el cubrebocas? 2,240\&nbsp;respuestas

Figura 17.

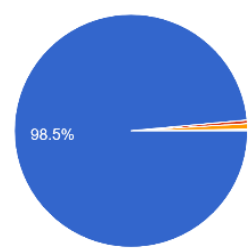

- Lo uso cubriendo nariz y boca - Lo uso cubriendo únicamente la boca Casi nunca utilizo cubrebocas - No utilizo cubrebocas 
¿En qué espacios usted suele utilizar de forma frecuente el cubrebocas?, el $84.9 \%$ (1902) selecciono la opción "Todas las anteriores (espacios públicos, transporte público, lugares de atención médica)", 13.5\% (303) dice utilizarlo en "Espacios públicos (plazas comerciales, supermercados, mercados y parques), $1 \%$ (22) solo en el transporte público, $0.4 \%$ (8) lo utilizan en "Lugares de atención médica (Hospitales, consultorios y farmacias)", la opción "Ninguna de las anteriores" no fue seleccionada (Figura 18).

¿En qué espacios usted suele utilizar de forma frecuente el cubreboca? 2,240\&nbsp:respuestas
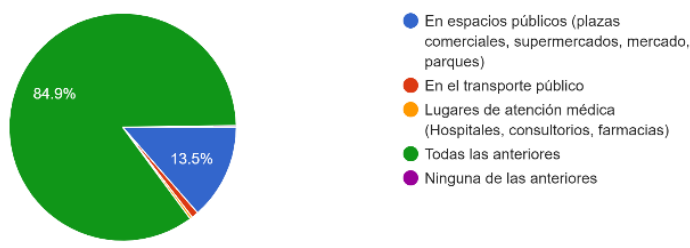

Figura 18.

¿Usted o las personas con las que vive, han enfermado de COVID-19? $87.8 \%$ (1966) respondieron que "NO" y $12.2 \%$ (274) respondieron que "SI".

\section{Discusión}

Dentro del estudio realizado las respuestas dadas por la Comunidad Universitaria nos permiten tener un panorama general de su conocimiento respecto a las medidas para prevenir la enfermedad por SARS-CoV-2, generando una base de datos relevante para estudios próximos o implementación de campañas preventivas necesarias.

Se realizaron preguntas para establecer las características generales de la población permitiendo conocer que más de la mitad de las personas encuestadas son mujeres, los rangos de edad con mayor participación corresponden a las edades de la comunidad de alumnos, sin embargo se tienen registros en todos los grupos de edad lo que nos permite una heterogeneidad en las respuestas. El lugar físico donde desempeña cada uno sus actividades nos parecen importante conocerlo ya que podemos identificar puntos de oportunidad para futuras intervenciones en salud.

Dentro de la evaluación del conocimiento de las medidas preventivas los resultados nos permiten concluir que la mayoría realiza un lavado de manos con agua y jabón sin embargo se puede reforzar el conocimiento de tiempo sugerido para su realización (tanto con agua y jabón como con alcohol gel). Otro punto de importancia para reforzar en futuras intervenciones es instruir a la población respecto a la cantidad correcta de cloro a usar para la limpieza de superficies y el número de veces que es recomendable realizarla.

El conocimiento de las medidas más fomentadas en estos meses (sana distancia, uso de cubrebocas y la desinfección contante de manos) se reflejó en las respuestas correspondientes siendo en su mayoría acertadas, sin embargo no debemos de disminuir su difusión.

Por último, se añadió la pregunta respecto a si habían presentado la enfermedad o habían estado en contacto con la misma dentro de sus hogares como sondeo general de la presencia de la COVID-19 en nuestra Comunidad Universitaria.

\section{Conclusiones}

Con los datos obtenidos podemos decir que gran parte de los encuestados cuentan con los conocimientos básicos acerca de medidas de protección para la prevención de la COVID-19, así como, la adecuada aplicación de las mismas en la vida cotidiana, en lo que conocemos como "nueva normalidad", éstas han sido estructuradas por diversos organismos e instituciones de salud tanto de nuestro país como por organismos internacionales y comparten muchos puntos en común, los cuales pueden verse sustentadas en el marco teórico de este documento. Los medios de comunicación y las estrategias mediante las cuales se ha difundido la información han sido los idóneos para que la comunidad perteneciente a la UAEH tenga acceso a ellos, de igual modo se han valido de estrategias sencillas y entendibles para que la aplicación sea la adecuada, el estudio del conocimiento y aplicación de las medidas básicas para prevenir el COVID-19 permite identificar las áreas de vulnerabilidad y oportunidad dentro de las medidas implementadas para cortar la transmisión de la COVID-19, esto a su vez permitirá elaborar nuevas estrategias sin dejar de lado las ya existentes, para que todos los sectores de la comunidad en este caso la universitaria cuenten con la herramientas necesarias para enfrentar la actual situación de salud pública que se está viviendo a nivel mundial.

Declaramos que no existe conflicto de interés entre los autores del artículo y las personas del equipo editorial de la revista.

\section{Referencias}

1] Organización Mundial de la Salud. (2020). Neumonía de causa desconocida - China. 04 de agosto del 2020, de Organización Mundial de la Salud Sitio web: https://www.who.int/csr/don/05-january-2020pneumonia-of-unkown-cause-china/es/ 
[2] Organización Panamericana de la Salud. (2020). Actualización Epidemiológica Nuevo coronavirus (COVID-19). 15 de julio del 2020, de Organización Panamericana de la Salud Sitio web: https://www.paho.org/hq/index.php?option=com_docman\&view=dow nload \&alias=51758-14-de-febrero-de-2020-nuevo-coronavirus-covid19-actualizacion-epidemiologica-1\&category_slug=2020-alertasepidemiologicas $\&$ Itemid $=270 \&$ lang $=e s$

[3] Organización Mundial de la Salud. (2020). Alocución de apertura del Director General de la OMS en la rueda de prensa sobre la COVID-19 celebrada el 11 de marzo de 2020. 04 de agosto del 2020, de Organización Mundial de la Salud Sitio web: https://www.who.int/es/dg/speeches/detail/who-director-general-sopening-remarks-at-the-media-briefing-on-covid-19---11-march-2020

[4] J. Reina. (2020). El SARS-CoV-2, una nueva zoonosis pandémica que amenaza al mundo. 04 de agosto del 2020, de ELSEVIER Sitio web: https://www.elsevier.es/es-revista-vacunas-72-pdfS1576988720300042

[5] Ranferi Aragón-Nogales, Iván Vargas-Almanza, María G. MirandaNovales. (02 marzo 2020). COVID-19 por SARS-CoV-2: la nueva emergencia de salud. Revista Mexicana de Pediatría, 86(6), 213-218.

[6] Kampf, G., Todt, D., Pfaender, S., \& Steinmann, E. (2020). Persistence of coronaviruses on inanimate surfaces and their inactivation with biocidal agents. The Journal of hospital infection, 104(3), 246-251. https://doi.org/10.1016/j.jhin.2020.01.022

[7] Fiorillo L, Cervino G, Matarece M, et al. (30 april 2020). COVID-19 Surface Persistence: A Recent Data Summary and Its Importance for Medical and Dental Settings. Int. J. Environ. Res. Public Health, 17, 3132, $1-10$

[8] World Health Organization. (2020). Water, sanitation, hygiene, and waste management for the COVID-19 virus. 30 de junio del 2020, de World Health Organization Sitio web: https://apps.who.int/iris/bitstream/handle/10665/331846/WHO-2019nCoV-IPC_WASH-2020.3-eng.pdf

[9] Secretaría de Salud. (2020). Proceso de Prevención de Infecciones para las personas con Covid-19 (enfermedad por SARSCoV-2), contactos y personal de la salud. 2 de julio del 2020, de Secretaria de Salud Sitio web: https://coronavirus.gob.mx/wpcontent/uploads/2020/04/Proceso_De_Prevencio\%CC\%81n_COVID19.pdf

[10] Rahmet G., İmran H., Firdevs A. (2020) COVID-19: Prevention and control measures in community. Turk J Med Sci, 50, 571-577. https://www.ncbi.nlm.nih.gov/pmc/articles/PMC7195988/

[11] Ellingston, K., PhD. (2014). Strategies to Prevent HealthcareAssociated Infections through Hand Hygiene. Infection Control and Hospital Epidemiology, 35(52), 1-21.

[12] Secretaria de Salud. Proceso de prevención de infección para las personas con COVID-19 (enfermedad por SARS-CoV-2). Contactos y personal de salud. (2020)._ https://coronavirus.gob.mx/wpcontent/uploads/2020/04/Proceso_De_Prevencio\%CC\%81n_COVID19.pdf

[13] Instituto Mexicano del Seguro Social. (2020). Infografía, Lavado de manos. 02 de agosto del 2020, de Instituto Mexicano del Seguro Social Sitio web: http://www.imss.gob.mx/salud-en-linea/infografias/lavadomanos

[14] Centro para el Control y la Prevención de Enfermedades. (2020). Enfermedad del Coronavirus 2019 (COVID-19). 15 de julio del 2020, de Centro para el Control y la Prevención de Enfermedades Sitio web: https://espanol.cdc.gov/coronavirus/2019-ncov/prevent-gettingsick/social-distancing.html

[15] Jarvis C, Zandvoort KV, Gimma A, Prem K, Klepac P, Rubin G, Edmunds W. Quantifying the impact of physical distance measures on the transmission of COVID-19in the UK. Jarvis et al. BMC Medicine (2020) 18:124 Disponible en: https://www.ncbi.nlm.nih.gov/pmc/articles/PMC7202922/

[16] Osorio González D. (2020) Medidas higiénicas para la prevención y manejo ambulatorio de contagios por COVID-19. 11 de junio del 2020, https://www.uaemex.mx/images/pdf/covid19/Medidas_higienicas_Covid-19-FINAL.pdf

[17] World Health Organization. (2020). Evidencia del impacto sobre la evolución de la epidemia de algunas medidas de control. Preguntas y respuestas sobre la enfermedad por coronavirus (COVID-19). $11 \mathrm{de}$ junio del $2020 \mathrm{https} / / / \mathrm{www}$.who.int/es/emergencies/diseases/novelcoronavirus-2019/advice-for-public/q-a-coronaviruses

[18] Umer F, Haji Z, Zafar K. Role of Respirators in Controlling the Spread of Novel Coronavirus (COVID-19) Amongst Dental Healthcare Providers: A Review. Int Endod J. 2020 May Citado en 26 de junio 2020. Disponible en:_https://pubmed.ncbi.nlm.nih.gov/32357257/

[19] Rotational use of masks in the COVID-19 pandemic. The Lancet Published online March 20, 2020. Disponible en: https://doi.org/10.1016/S2213-2600(20)30134-X

[20] Roger Chou, Tracy Dana, Rebecca Jungbauer, Chandler Weeks, Marian S. (2020). Masks for Prevention of Respiratory Virus Infections, Including SARS-CoV-2, in Health Care and Community Settings. 10 de julio del 2020, de Annals of Internal Medicine Sitio web: https://www.acpjournals.org/doi/10.7326/M20-3213

[21] Jessica J. Bartoszko, Mohammed Abdul Malik Farooqi, Waleed Alhazzani, Mark Loeb. (1 April 2020). Medical masks vs N95 respirators for preventing COVID-19 in healthcare workers: A systematic review and meta-analysis of randomized trials. Influenza Other Respi Viruses, 14, 365 - 373.

[22] Raina MacIntyre and Abrar Ahmad Chughtai. (21 April 2020). A rapid systematic review of the efficacy of face masks and respirators against coronaviruses and other respiratory transmissible viruses for the community, healthcare workers and sick patients. International Journal of Nursing Studies, 108, 1 - 7.

[23] Zayas, G., Chiang, M. C., Wong, E., MacDonald, F., Lange, C. F., Senthilselvan, A., \& King, M. (2013). Effectiveness of cough etiquette maneuvers in disrupting the chain of transmission of infectious respiratory diseases. BMC Public Health, 13(1), 1471-2458. https://doi.org/10.1186/1471-2458-13-811

[24] Choi, J. S., \& Kim, K. M. (2016). Predictors of respiratory hygiene/cough etiquette in a large community in Korea: A descriptive study. American Journal of Infection Control, 44(11), e271-e273. https://doi.org/10.1016/j.ajic.2016.04.226 